\title{
Water as our life and Helper
}

\author{
Kirill N Voinov ${ }^{1 *}$ and Altyn Zh Esbulatova ${ }^{2}$ \\ ${ }^{1}$ Professor, Universities ITMO \& GASU, Saint-Petersburg, Russia \\ ${ }_{2}^{2} J u n i o r$ member of teaching, West Kazakhstan Agrarian-technical University, Kazakhstan
}

Submission: June 19, 2020; Published: July 02, 2020

"Corresponding author: Kirill N Voinov, Professor, Universities ITMO \& GASU, Saint-Petersburg, Russia

\begin{abstract}
As we know, people constantly seek the planet where is maybe even very small amount of water. We usually assure why a man try to find a planet where the water is present: because of the water is life. Many scholars suppose that if in the definite place there is water and there is any life. And they are right. It is common knowledge, that water is the real source of life. But it helps us to get different food (fish /with meet and fat, salt, chemical elements, edible seaweeds and so forth /). We use it in many technological processes (in metallurgy, medicine, roadbuilding, in hydraulic systems, preparing our food and so on). Moreover, water permits to diminish the bad influence from the carcinogenic exhaust gases and harmful evaporations. Especially attention in this article it will be devoted to save fresh air against poison gases and bad evaporations for the people and living creatures using for this important aim only water.
\end{abstract}

Keywords: Water; Exhaust gases; Harmful evaporations; Protection both health and environment

\section{Text 1}

Firstly, let's remember the main role of water for our life in brief of course. Here they are several examples:

i. It is extremely needed to drink water and to remove the thirst for the man.

ii. To boil eggs, soup, kasha, fruit drink and so on.

iii. To wash our body, face, hands, hair,

iv. To use in the medical aims (as a massage, to calm our nerves or to wake up very quickly).

v. To pour water on something (ground, trees, bushes, flowers, windows, floor, car and so on).

Very often we use water in many different technological processes, namely:

i. To make the thermal treatment for steel to get the definite structure and properties.

ii. To cool off the hot motor/engine or another system.

iii. To get many chemical compositions and medical preparations.

iv. To apply water as a force in the different hydraulic systems. v. To use the energy of water in the hydro-electric power station.

As usually, all of these applications of water we know very well. But the next very important application of water for our health and how to save the environment against of the very harmful gases and bad evaporations will be given below [1-4].

\section{Text 2}

You certainly know that very many harmful gases fly out in the atmosphere from the pipes (works, factories, boiler-houses, diesel locomotives and so on). The next picture Shows how we can catch these gases and even neutralize them in full (Figure 1).

\section{Conventional signs}

1 - various enterprises; 2 - the main pipe with a pump to suck off harmful gases and doesn't permit them to go into the atmosphere; 3 - reserve pipe to suck bad gases with a pump as well; 4 - chemical gas analyser with two sections; 5 and $5 /-$ valves/bolts; 6 and 6/ - valves; 7 - two-section and the basic capacity; 7/ - additional reserve two-section reservoir; 8 - the ways to clear away the gathered tailings from the main capacity; 8/ - the ways to clear away the wasted chemical products from the reserve capacity; 9 and 9/ - pipes to give special chemical 
elements or chemical compositions into the water to neutralize the harmful gases. The bold lines show the main way to clean gases, but the thin lines show the reserve itinerary. Routs/ways 8 and 8 / permit not only to delete chemical products but they allow for the workers/staff enter the capacity to repair the reservoir.
Reserve systems in this principle chart permit to repair the main way of transportation for gases and besides to clean and repair the main capacity. There is the full and over-all system to neutralize any harmful gases in full.

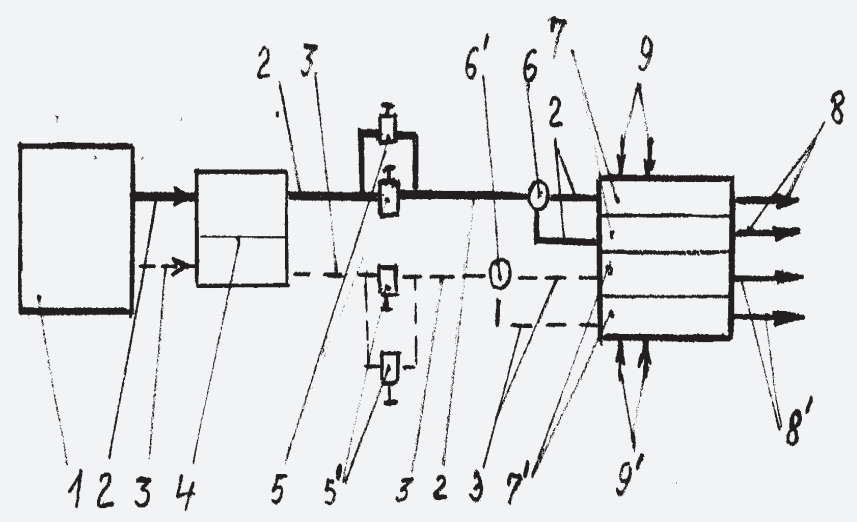

Figure 1: Principle chart is shown in here to protect the clean air against any gases from the industrial enterprises.

\section{Text 3}

\section{Physical model to catch harmful evaporations}

Only completely hermetic mechanical system permits us to catch all harmful gases and evaporations defending our health/ life and environment. The experiments were made with rather dangerous liquids as benzene, kerosene and even benzol. For these two reservoirs (big and small) by means of a pipe were connected (Figure 2). Moreover, this design does not permit to disappear for any evaporations because of the obstacle for them to fly out into atmosphere freely. The next chart of such working principle is shown below (Figure 3) [5-8].

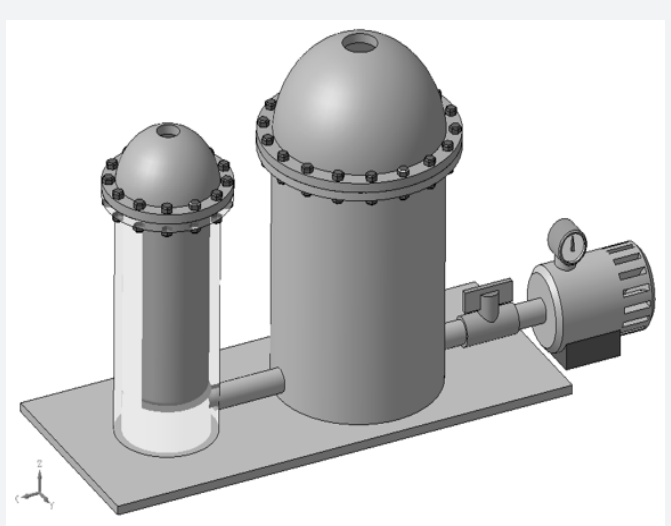

Figure 2: Technical hermetic system to protect against harmful and poison evaporation from different liquids.

Conventional signs: 1 - pump; 2 - valve; 3 - nozzle; 4 - trunk of the main capacity to keep the big volume of liquid or gas; 5 thin and gas-proof film which has a defence against the aggressive products; 6 and 13 - flanges; 7 and 14 - bolt strengthening; 8 and 15 - caps; 9 and 16 - openings in caps; 10 - connective nozzle; 11 - transparent trunk of the auxiliary capacity (as a device of a control for the level / volume of liquid product); 12 - thin film as the same to the number 5 .

From the expounded material about this technical hermetic system (Figure 2) there is the next important result, namely: all reservoirs have the hermetic design; all harmful gases or bad evaporations are inside of this system and not on the open air; it does not permit to spoil our health and the environment. The small capacity/reservoir works as an indicator to show the level of the liquid product in the big capacity. For this the wall of this small capacity is transparent. Thin films do not permit for the poison gases or/and aggressive evaporations go into the clean air at all. 


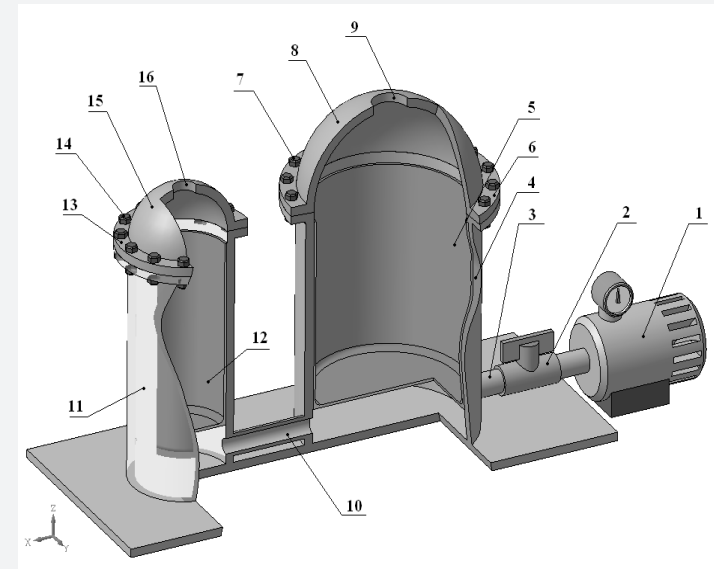

Figure 3: The cross-section of the new system to catch any evaporations (especially dangerous) in full.

\section{Text 4}

At last the information about how to catch exhaust gases from the cars which stand motionlessly but the motor has an idling (maybe, in a lab, in a station where workers try to repair the engine and so on).

In this case the next effective way to save our health and environment against the harmful exhaust gases and evaporations can be suggested (Figure 4).

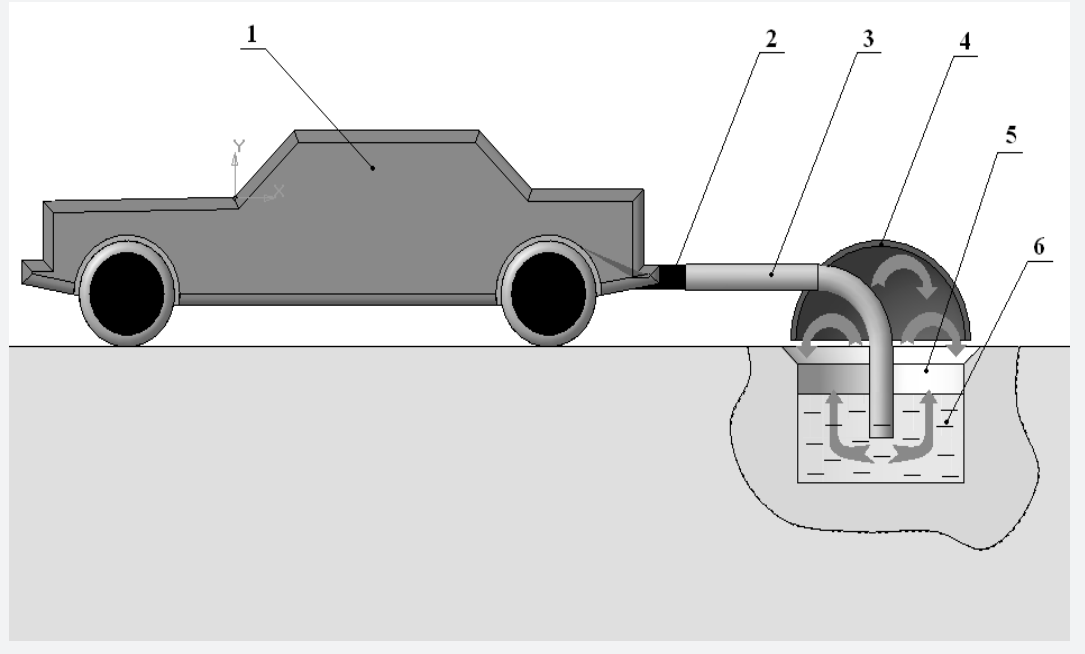

Figure 4: Principle chart is shown in here to protect the clean air against of the exhaust gases from the transport vehicle.

\section{Conventional signs}

1 - motor vehicle; 2 - exhaust pipe; 3 - hose or tube to the movement for the exhaust gases; 4 - cover/awning to impede for the gases fly freely into the open air if some amount of gases wouldn't catch in full into the water capacity; 5 - oil (or another medium) which can neutralize or delay any harmful gases/ evaporations; 6 - water in the capacity/reservoir.

The experiments show that the minimum thickness of the industrial oil on the surface of water must be not less than $15 \mathrm{~mm}$. In this case practically all gas bubbles will be under the oil layer. Another positive effect for ecology is the next: water effectively diminishes temperature of the hot exhaust gases to normal and it doesn't overheat the air. At last, the full hermetization in the zone where the vehicle is standing with the motor which is working can be if we'll use the additional hermetic thin film which freely cover this place. The film must have a valve to take the evaporations periodically to neutralize them by means of the traditional ways. 


\section{Conclusion}

Thus, all problems connected with any harmful gases or/ and evaporations can be easily solved using water. As the patent search shows that it is not any better decision of this problem in the world at the present day that's why this technical novelty must be realize in practice.

\section{References}

1. Voinov K (2018) Patent. Snare for the harmful evaporations and smells pp. 2656458.

2. Voinov K (2019) Patent. Way to catch and clear the exhaust gases pp. 2705354.

3. Voinov K (2015) Patent. The way to clean air reservoir in the over-all version from the industry gases pp. 2604816.

4. Voinov K (2016) Patent. The working principles to save the hot part using load-seizure pp. 2627223.

5. Voinov KN, Vasil'ev VA, Hildayati A, Ghellab Y (2017) New way to diminish the pollution in the air space. International encyclopaedia "Tribology”, Vol. XII edited by prof. KN Voinov. SPb., Nestor History pp. 130-133.

6. Voinov KN, Ghellab Y (2017) About pollution from gases because of the motor tubes. International encyclopaedia "Tribology", edited by prof. Voinov KN. SPb., Nestor History 12: 127-129.

7. Voinov KN, Hildayati A, Ghellab Y (2017) Ways to protect the air against the harmful gases which are flowing from the industrial tubes and from the exhaust pipes. World science: Proceedings of articles the international scientific conference (Karlovy Vary-Moscow, 29-30. 06. 2017г) p. 71-75.

8. Voinov KN, Hildayati A, Ghellab Y (2017) Ways to defend the fresh air against gases going from the industrial enterprises, boiler-houses and from the motor vehicles. Global Journal of Researches in Engineering 17(4): 55-59.

Your next submission with Juniper Publishers will reach you the below assets

- Quality Editorial service

- Swift Peer Review

- Reprints availability

- E-prints Service

- Manuscript Podcast for convenient understanding

- Global attainment for your research

- Manuscript accessibility in different formats

( Pdf, E-pub, Full Text, Audio)

- Unceasing customer service

Track the below URL for one-step submission https://juniperpublishers.com/online-submission.php 